\title{
Research and Development of Transportable Coastal Radar at S-band Frequency with FM-CW Technology for Supporting C4ISR
}

\author{
Mashury Wahab, Yussi Perdana Saputera, and Yuyu Wahyu \\ Research Centre for Electronics and Telecommunications of \\ The Indonesian Institute of Sciences (RCET-LIPI), \\ Sangkuriang road, Building 20, $4^{\text {th }}$ Floor, Indonesia \\ mashury.wahab@gmail.com, yussips@gmail.com
}

\begin{abstract}
In this paper, a research on coastal Radar to support C4ISR (Command, Control, Communications, Computers, Surveillance and Reconnaissance) was carried out.This coastal Radar has an advantage of easy to be transported in order to observe seas/coastal areas in different locations. The Radar technology used in this research is FMCW (frequency modulated continuous wave) with a S-band working frequencies, where this type of Radar has a LPI (low probability of intercept) capability. In this paper, the presentation is on antenna and hardware development, while the radar software is currently still on progress for the installation. The Radar consists of antenna system (dual antenna), an antenna moving parts (stator + motor), the high frequency part of RF (radio frequency), power supply, rotary joint for connecting between the RF with antenna, down converter to convert the signal RF to IF (intermediate frequency), power splitter 3-1 and 1-3 serves as a multiplexer and de-multiplexer. The mux/de-mux connects to the signal processing part of IF, part of the data processing and Radar signal, and the Radar display. The designed and fabricated antenna system produces bandwidth of $61.25 \mathrm{MHz}$, VSWR at 3 $\mathrm{GHz}=1.303$, one degree of horizontal angle and vertical angle of 19.6 degrees. The measurement results show a similarity between the designed and the measured antennas, i.e., the vertical beamwidth $<20^{\circ}$ and antenna gain array of $27.52 \mathrm{dBi}$.
\end{abstract}

Keywords-component;radar; coastal; radio frequency; antenna; continuous wave.

\section{INTRODUCTION}

Surveillance and navigation of Indonesian waters, which consist of more than 17.000 islands and $2 / 3$ of them are seas, will be greatly helped by the use of a marine Radar. High transmitted power Radars on coastal areas can be used to monitor the seas up to tens of nautical miles or until the border of economic exclusive zone. At the moment, a transportable coastal Radar using FM-CW technology is under development and one of the primary researches at the RCET-LIPI.

Indonesia as shown in the map on Figure 1 is surrounded by many countries including Singapore, Malaysia, Philippine, New Guinea and Australia. There are a lot of activities occurred in the Indonesian waters including legal and illegal activities. The security and transportation safety can be increased by the use of coastal Radar along the Indonesian coastal lines and at the remote Island close to boundary region.

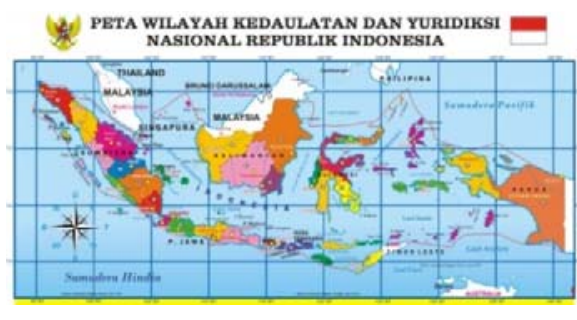

Figure 1. Indonesianmap.

\section{BASIC THEORY}

A. Radar FM-CW (frequency modulated continuous wave)

The FM-CW radar systememits and receives the radio signals all the time. Almost all the time here can be interpreted as at least $10 \%$ of the time spent by the signal to reach target. This is a very large percentage compared to that normally used in radar pulses, where the energy emitted is usually less than $0.1 \%$ of the time. Thus, to obtain the same average received by the target, the pulse radar transmitter output power requires far greater than the power output of an FM-CW radar transmitter [1], [2], [3].

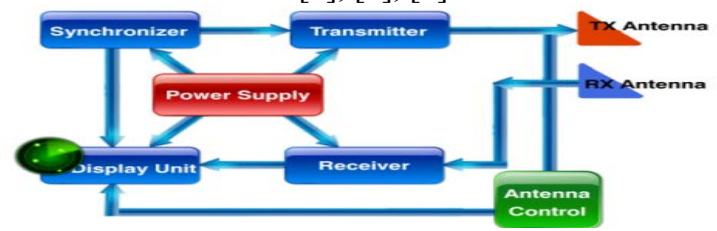

Figure 2. Radar system block diagramRCET-LIPI.

\section{SYSTEM DESIGN}

B. Specifications Transportable coastal Radar

Researchspecificationsof coastalRadar [6], [7], [8] :

1) Transmitter:

- Frequency: $\mathrm{S}$ band $(2.8-3.1 \mathrm{GHz})$.

- $\quad$ Ranges: $48 \mathrm{Km}, 24$ km, $12 \mathrm{Km}, 6 \mathrm{Km}, 3 \mathrm{Km}$.

- Output power: 50 Watt.

2) Receiver:

- IF bandwidth: $512 \mathrm{kHz}$.

- Number of range cells: 512 .

- Range cells: 125 m, 62 m, 31 m, 12 m, 6 m.

- $\quad$ PC-Based processing system.

- Standard PC display. 
- $\quad$ Maximal beat frequency $2 \mathrm{MHz}$.

- Beat signal sampling by 16 bit ADC

3) Frequency Generation

- Main frequency generator DRO (dielectric resonant oscillator).

- FM-Modulation.

- Linear saw-tooth by using DDS (direct digital synthesizer).

- $\quad$ Sweep (Sweep Repetition Frequency): 1,5 KHz.

- Fixed sweep time of $0.66 \mathrm{~ms}$

- $\quad$ Frequency Sweep: $2 \mathrm{MHz}, 4 \mathrm{MHz}, 8 \mathrm{MHz}, 16 \mathrm{MHz}$, $32 \mathrm{MHz}$.

4) Antenna:

- Microstrip Patch array with gain $\sim 30 \mathrm{~dB}$.

- Dual antenna configuration for transmitand receive.

- Azimuth range: 180 degree

- Elevation range: -5 degree up to 10 degree

- Beamwidth: $<1$ degree.

- Vertical beamwidth: $\sim 10$ degree.

5) Software : IMO Standard + ARPA+ ECDIS

6) Features of Transportable coastal Radar

- Low transmit power $(<=50 \mathrm{~W})$

- Low Probability of Intercept (LPI) Radar

- No interference to other Radars

- Target tracking

- Doppler capability

- Able to be integrated into a Radar network

\section{Design of TransportableCoastalRadar}

Figure 3 shows the design of a portable coastal Radar can be stand alone (stand alone / not depending on the vehicle), where there is a container that contains the Radar system including all electronic devices, radio frequency, computer + display, power supply, and a device for the ascending Radardown. Behind this container there is a system generator to provide electrical power supplies. Containers and generator will be drawn using a vehicle such as a truck [6].

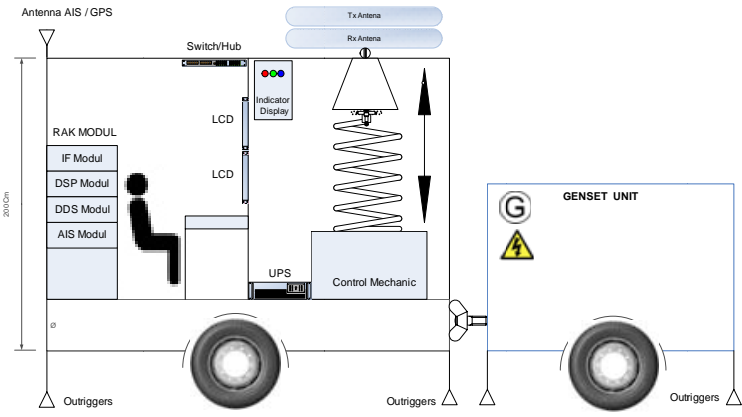

Figure 3. Design of coastal radar by RCET-LIPI.

\section{Antennadesign}

In this research, we used FR4 as the substrate with the er of 4.4 and thickness of $3.2 \mathrm{~mm}$. The design of this antenna is depicted on Figure 4.

Rectangular patch, W can be enlarged to cope with radiation from the edge of the patch. While $L$ must be $<\lambda / 2$, where $\lambda$ is the wavelength of the dielectric medium.

$$
\mathrm{W}=\frac{2}{2 \mathrm{f}} \sqrt{\frac{2}{\varepsilon \mathrm{r}+1}}
$$

Where $\lambda 0$ is the vacuum wavelength and creff is effective dielectric constant patch. ereff value can be obtained from the equation:

$$
\varepsilon_{\mathrm{eff}}=\left(\frac{\varepsilon_{\mathrm{r}+1}}{2}\right)+\left(\frac{\varepsilon_{\mathrm{r}-1}}{2}\right)\left(\frac{1}{\sqrt{1+12 \mathrm{~h} / \mathrm{W}}}\right)
$$

To find the length $\mathrm{L}$ can be used the following equation :

$$
\begin{aligned}
& \frac{\Delta \mathrm{L}}{\mathrm{h}}=0.412 \frac{\left(\varepsilon_{\text {reff }}+0.3\right)\left(\frac{\mathrm{W}}{\mathrm{h}}+0.264\right)}{\left(\varepsilon_{\text {reff }}+0.258\right)\left(\frac{\mathrm{W}}{\mathrm{h}}+0.8\right)} \\
& \mathrm{L}_{\text {eff }}=\frac{\mathrm{c}}{2 \mathrm{f} \sqrt{\varepsilon_{\text {eff }}}} \\
& \mathrm{L}=\mathrm{L}_{\text {eff }}-2 \Delta \mathrm{L}
\end{aligned}
$$

Ground plane size equal to the size of the substrate:

$$
\begin{aligned}
& \Lambda \gamma \varepsilon 6 \eta+\Lambda \\
& \Omega \gamma \varepsilon 6 \eta+\Omega
\end{aligned}
$$

After getting the antenna dimensions can be determined impedance $\mathrm{Zr}=\mathrm{Rr}+\mathrm{Xr}$ half-wave resonance radiation patch of square patch antenna "formula Jackson and Alexopolus" $[5]$.

$$
\mathrm{R}_{\mathrm{r}}=90\left(\frac{\varepsilon_{\mathrm{r}}^{2}}{\varepsilon_{\mathrm{r}}-1}\right)\left(\frac{\mathrm{L}}{\mathrm{W}}\right) \Omega
$$

Dan, $\mathrm{Xr}=0$

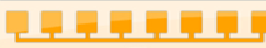

Figure 4. One module antenna construction by RCET-LIPI

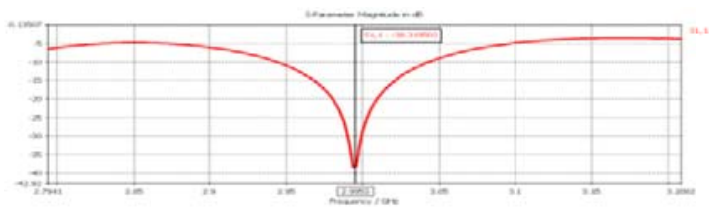

Figure 5. Simulated of return loss

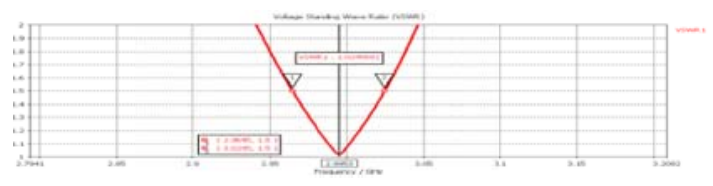

Figure 6. Simulated of VSWR 


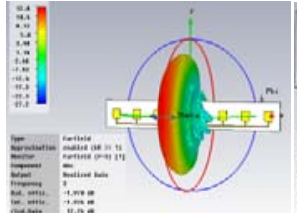

(a)

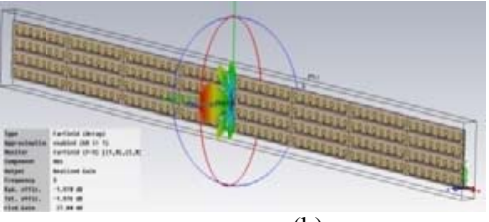

(b)
Figure 7. (a) Simulated gain one antenna $12.76 \mathrm{~dB}$, (b) Simulated planar array $4 \times 8$ by RCET-LIPI

For planar antennas are arranged, generating a gain of $27.86 \mathrm{dBi}$

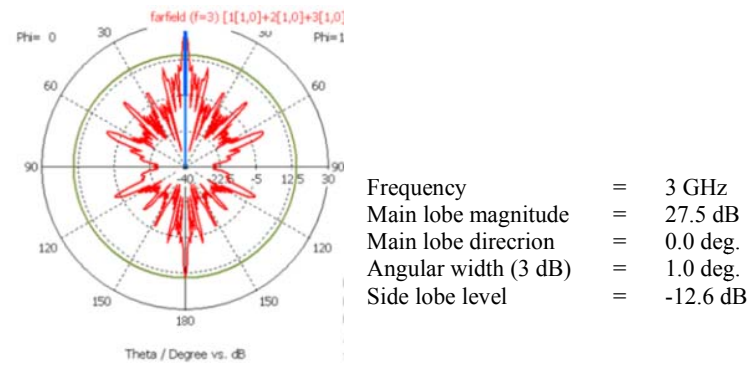

Figure 8. Azimuth $3 \mathrm{~dB}$ beamwidth angle result

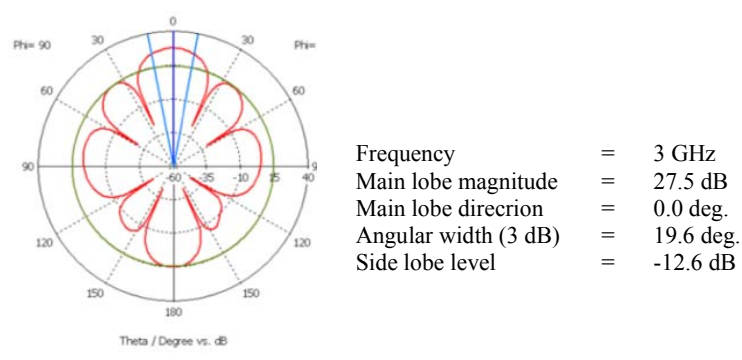

Figure 9. Elivation $3 \mathrm{~dB}$ beamwidth angle result

Simulation of planar antenna, acquired $3 \mathrm{~dB}$ beamwidth azimuth angle of $1^{\circ}$, while the $3 \mathrm{~dB}$ beamwidth elevation angle of $19.6^{\circ}$.

\section{E. Antennamechanicalsystemdesign}

Based on the results of research that used radar antenna as the coastal radar antenna consisting of $8 \times 4$ modules are arranged in a planarantenna. the mounting position can be seen in the image below. The above picture presents the design of the drive system for a portable coastal radar antenna. Antenna used is a $8 \times 4$ antenna array that was described in the previous explanation.

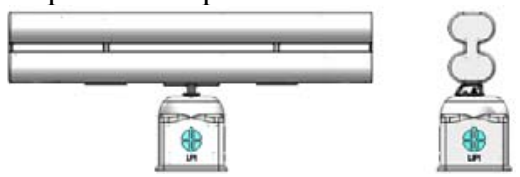

Figure 10. Radome design antenna system RCET-LIPI

Radom serves as a protective antenna from weather, such as rain, heat, and dirt. So the antenna will not be exposed to corrosion and can last a long time.

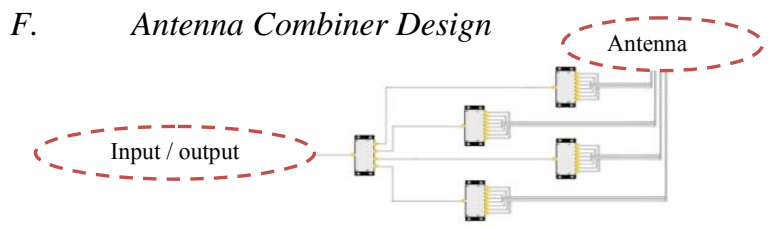

Figure 11. Antenna combiner design by RCET-LIPI

The above image is a composition of an antenna combiner, good for receiver antenna or transmitter antenna. For transmitting antenna combiner designed using 5 pieces, namely combiner 1 to 4 and 1 to 8 . So that on the whole there are 10 antenna combiner.

\section{REALIZATION AND MEASUREMENT}

\section{A. Antenna Realization}

In the study conducted, simulating for transportable coastal Radar antenna working at a frequency of $3 \mathrm{GHz}$. Antenna simulation results then fabricated using FR-4 material having er value of 4.4 to substrate thickness $=3.2$ $\mathrm{mm}$. Antenna module fabrication results can be seen in the image below.

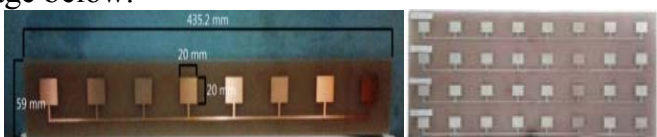

(a)

(b)

Figure 12.(a) Antenna realization by RCET-LIPI, (b) Antenna realization $1 \times 4$ for 1 module by RCET-LIPI.

1 module design of antennas used are 4 flats planar, so that was fabricated antenna module into 4 pieces 1 , can be seen in the image below.

\section{B. MechanicalRealization}

Mechanics are made using aluminum-framed, with size adjusted to the overall antenna size ( $8 \times 4$ modules) for antenna transmitter or receiver antenna. transmitter and receiver antennas have a range called Air gap. Air gap serves to reduce the isolation which is derived from each antenna.
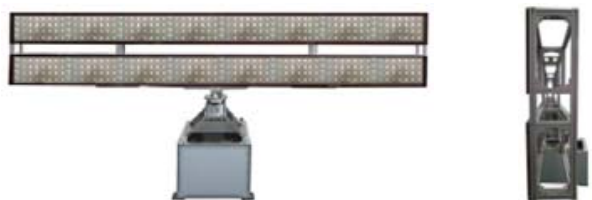

Figure 13. Realization antenna 64 module (TX and RX) by RCET-LIPI.

\section{S-band RF systemRealization}

The Radar is designed to work on a $3 \mathrm{GHz}$ frequency band or S-band. Radar development was started by manufacturing of circuit design, the gain calculation, ordering materials including imported components and the results of its own assembly (local content), integration, and ending with testing or measurements. Frequency radio system is realized as follows:

- LNA (Low Noise Amplifier)

- Bandpass Filter

- Mixer 
- $\quad$ IF (Inter Mediate) Amplifier

- IF Filter

- Phase Detector

- Bandpass Filter Beat frequency

- Beat amplifier

With Receiver Specification s-Band Radar of Realized:

- frequency center : $3 \mathrm{GHz}(\mathrm{BW} 60 \mathrm{MHz})$

- Impedance Input : $50 \Omega$

- Sensitivity : $-100 \mathrm{dBm}(0 \mathrm{~dB} \mu \mathrm{V})$

- Dynamic Range : $40 \mathrm{~dB}$ (70 dB with attenuator)

- Conversion Gain : $70 \mathrm{db}-77 \mathrm{db}$

- IF (intermediate Frequency) : $600 \mathrm{MHz}$

- $\mathrm{S} / \mathrm{N}$ ratio : $18 \mathrm{db}$

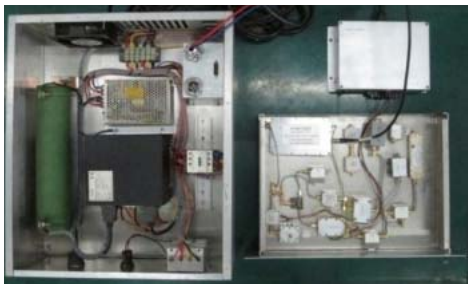

Figure 14. Radar system, motor driver, frequency generator and power amplifier by RCET-LIPI.

Modules and components that have been developed for the integrated frequency generator section are: Main frequency generator (DRO), $2.4 \mathrm{GHz}$ signal generator, splitter 4, splitter 6, filters $400 \mathrm{MHz}, 20 \mathrm{~dB}$ Coupler and Splitter 2.4. Figure 15 (a) states the frequency generator section assembly.

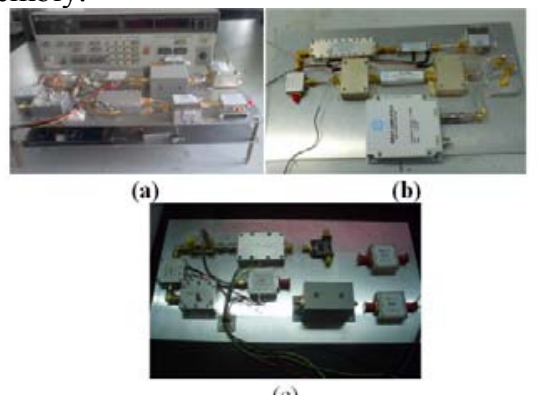

(c)

Figure 15. Assembly frequency generator and transceiver.

Figure 15 (b) shows the development of transmitters (including the frequency generator). The transmitter consists of an up-converter mixer, band pass filter, step attenuator, 2 $\mathrm{W}$ power amplifier, coupler and power detector. Receiver assembly are shown in Figure 15 (c). The receiver section consists of: Low noise amplifiers, band pass filter, downconverter mixer, IF amplifier, IF filter, IF mixer, a low frequency band pass filters, and amplifiers beat. On the development of frequency generator, transmitter, and receiver, some modules have been made by RCET-LIPI beat amplifier, IF filter, and IF amplifier.

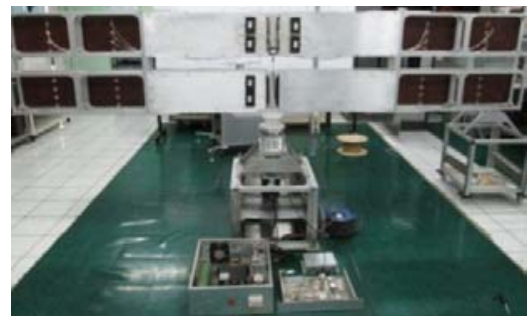

Figure 16. Overall radar antenna system, motor driver, frequency generator and power amplifier

\section{Antenna Measurement}

Antenna measurement carried out in the laboratory of telecommunications PPET-LIPI. Tool used to measure the antenna VSWR is a network analyzer that operates at a frequency of $50 \mathrm{MHz}-20 \mathrm{GHz}$.

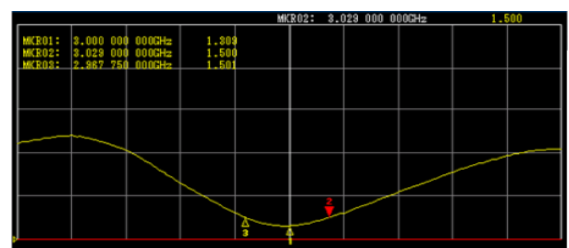

Figure 17. Results of VSWR measurement antenna

The value of VSWR $\leq 1.5$ obtained in the frequency range from 2.967750 to $3.029 \mathrm{GHz}$ so that the bandwidth of antenna is $61.25 \mathrm{MHz}$. This shows that the designed antenna meets the specifications set has a bandwidth of $60 \mathrm{MHz}$.

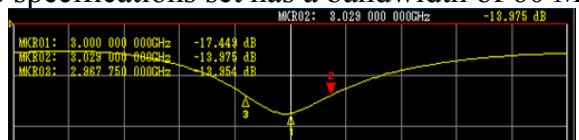

Figure 18. Results of return loss measurment

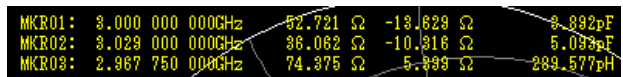

Figure 19. Results of antenna impedance

Impedance of the antenna at a frequency of $3 \mathrm{GHz}$, resulting impedance of $52 \mathrm{ohms}$, this shows that the antenna has an impedance that is made is within their specification antenna is determined, that is equal to $50 \mathrm{ohms}$.

Antenna radiation pattern is a representation of a comparison of levels of power out of the antenna in various directions. Antenna radiation pattern is measured at the antenna far-field region, due to the area that radiates electromagnetic waves are transverse full. The radiation pattern is measured by placing the antenna vertically or horizontally. 


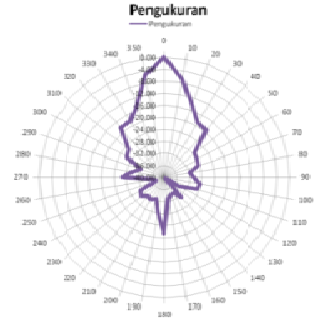

(a)

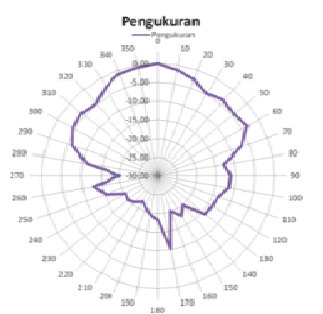

(b)
Figure 20.(a) Azimuth measurement, (b) Elevation measurement

Within Measurement azimuth, angle which obtained $\pm 12^{\circ}$, on simulation to come by $12.4^{\circ}$, with specifications which in specify in under $20^{\circ}$ for every its module.In measurements of elevation, angle obtained $\pm 58^{\circ}$, the simulations obtained $87.7^{\circ}$, with specifications as specified under $90^{\circ}$ to each module.

\section{E. RF systemMeasurement}

Block diagram measurement for frequency generator and transmitter expressed in Figure 21. Level inputs and outputs on each module measured included frequency. This measurement is done by using a spectrum analyzer and signal generator. The input of spectrum analyzer is attenuated by $14 \mathrm{~dB}$ in order to prevent damage to the components.

Composition measurement Radar receiver is shown in Figure 23. On these measurements, the most important parameter is the sensitivity of the receiver, where the parameters related to antenna and power amplifier, determine the range of the Radar (range). Results of the measurements are shown in Table 1.

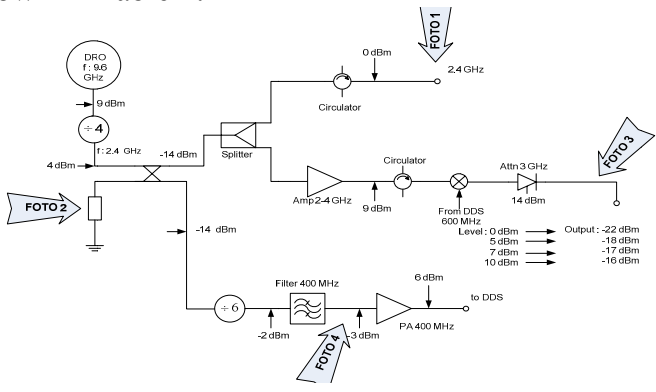

Figure 21. Block diagram of the measurement

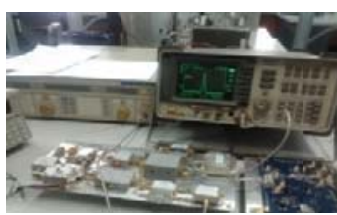

Figure 22. Measurement arrangement

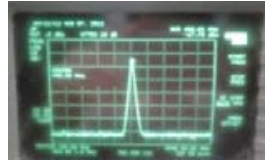

(a) $400 \mathrm{MHz}$ In. to DDS

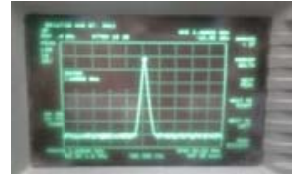

(b) Oscillator out. of $2.4 \mathrm{GHz}$

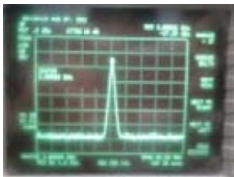

(c) $3 \mathrm{GHz}$ input to $\mathrm{PA}$

Figure 23. Measurement results

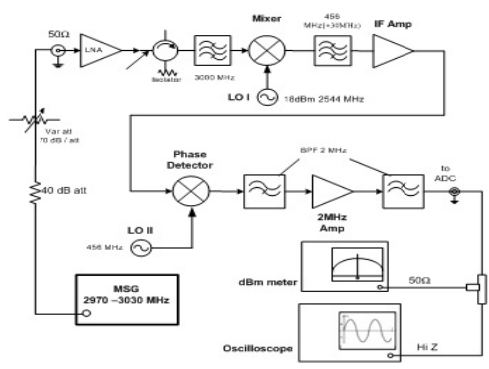

Figure 24. Measurement setup for receiver

TABEL 1. RESULTSMEASUREMENTRECEIVER

\begin{tabular}{|l|l|l|l|l|}
\hline No & \multicolumn{1}{|c|}{ Parameter } & $\mathbf{d B}$ & $\mathbf{d B m}$ & Remark \\
\hline 1 & Sensitivity & & -100 & \\
\hline 2 & Gain conversion & 77 & & \\
\hline 3 & Range dynamic & 45 & & \\
\hline 4 & Response Baseband & 0.5 & & $200 \mathrm{KHz}-1.7 \mathrm{MHz}$ \\
\hline
\end{tabular}

\section{CONCLUSION}

Design and development of S-Band transportable coastal Radar was presented. In this paper, the presentation is on antenna and hardware development, while the Radar software is currently still on progress for the installation. Based on the results of simulation and measurement, the results are similar for both approaches. Parameters obtained for the system antenna were VSWR of 1.303 at a frequency of $3 \mathrm{GHz}$, bandwidth of $61.25 \mathrm{MHz}, 52 \mathrm{Ohm}$ impedance, $11.58 \mathrm{dBi}$ antenna gain, and the elevation angle (beamwidth) of $17^{\circ}$. The measurement results for other hardware such as receiver are described in the paper. This research is expected to enhance and contribute to the Radar research in Indonesia.

\section{ACKNOWLEDGEMENT}

This research was performed in cooperation with the University of Indonesia for the use of simulation software. The funding for this research comes from the internal research funding of the RCET-LIPI. We thank to all parties that help in completing this research.

\section{REFERENCES}

[1] Leo P. Ligthart, 'Short Course on Radar Technologies', International Research Centre for Telecommunicationstransmission and Radar, TU Delft, September 2005.

[2] M. Wahab dan P. Daud, 'Image Processing Algorithm for FM-CW Radar', TSSA/WSSA Conference 2006, ITB Bandung, 2006. 
[3] M. Wahab, Pamungkas Daud, Y. Wahyu, Y. N. Wijayanto, "Radar Trainer System for LIPI FM-CW Radar Network", ICICI 2007, Bandung.

[4] M.I. Skolnik, 'Radar Handbook', McGraw-Hill, 1990.

[5] Jackson, D. R. and N. Alexopoulos, "Simple approximate formulas for input resistance, bandwidth and efficiency of a resonant rectangular patch" IEEE Transactions on Antennas and Propagation, Vol. 39, 409, March, 1991.

[6] M. Wahab, " Design and Simulation of High Performance Low Noise Amplifier for FM-CW Radar," Journal of Electronics and Telecommunications of PPET-LIPI 2009, Bandung.

[7] Y. Wahyu, F. Oktafiani, Y. P. Saputera, and M. Wahab, "Seminar Nasional SMAP 2012" Universitas Indonesia, Depok, 2012.
[8] Y. Wahyu, M. Wahab. And Y. P. Saputera, "The 3 Makassar International Conference on Electrica Engineering and Informatics (MICEEI) 2012 rd”, Makassar, 2012.

[9] Y. P. Saputera, Y. Wahyu, dan M. Wahab, "Spiral Antena for Electronic Support Measures (ESM) Application 2-18 GHz", ICRAMET, Surabaya, 2013, in Proc. ICRAMET, Surabaya, 2013, pp. $35-39$.

[10] S. M. Metev and V. P. Veiko, Laser Assisted Microtechnology, 2nd ed., R. M. Osgood, Jr., Ed. Berlin, Germany: Springer-Verlag, 1998.

[11] Y. Wahyu, Y.P. Saputera, dan I. D. P. Hermida, "Array Planar Antenna Using Thick Film on Alumina Substrate for X-band Radar", ICRAMET, Surabaya, 2013, in Proc. ICRAMET, Surabaya, 2013, pp. $30-34$. 